FINAL REPORT

U.S. Department of Energy

\title{
INTERFACIAL RADIOLYSIS EFFECTS IN TANK WASTE SPECIATION
}

\author{
Thom M. Orlando \\ School of Chemistry and Biochemistry \\ Georgia Institute of Technology \\ Atlanta, GA 30332-0400; (404) 894-4012 \\ Dan Meisel \\ Notre Dame Radiation Laboratory \\ University of Notre Dame \\ Notre Dame, IN 46556-0579 \\ Donald M. Camaioni \\ Pacific Northwest National Laboratory \\ Richland, WA 99352
}

Project Number: 54646

TTP Number: RL37SP22

Grant Project Officers:

Mr. Jose Elizondo, Idaho Falls, Phone: (208) 526-0965

Dr. Richard Gordon, Office of Science, DOE (301) 903-8014

Project Duration: October 1996-September 1999 


\section{Table of Contents}

1.0 RESEARCH OBJECTIVE..................................................................................................................................................................

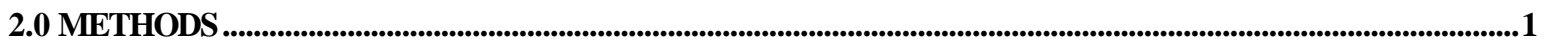

3.0 RESEARCH RESULTS...........................................................................................................................................................

3.1 EleCtron BeAm INTERACTIONS WITH $\mathrm{NANO}_{3}$ SURfaCeS AND INTERFACES ...................................................

3.2 RADIOLYTIC EFFECTS OF SOLID PARTICLES ............................................................................................

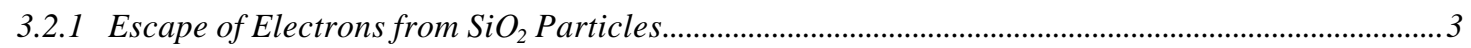

3.2.2 Trapping of Holes in the Particles .................................................................................................

3.2.3 Control of Charge Escape by Surface Modifications....................................................................

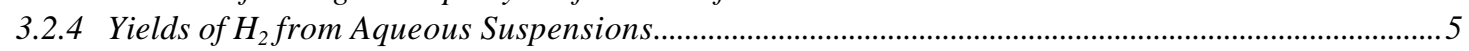

4.0 RELEVANCE AND IMPACT..........................................................................................................................................5

4.1 Gas Generation and Organic/Nitrate TankS at EM Sites ........................................................................

4.2 ORGANIC LAYER IN THE TANKS AT THE IDAHO NATIONAL ENGINEERING LABORATORY .......................................6

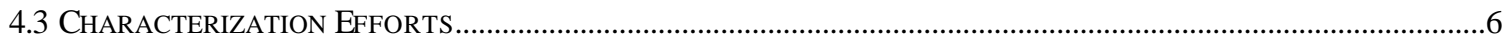

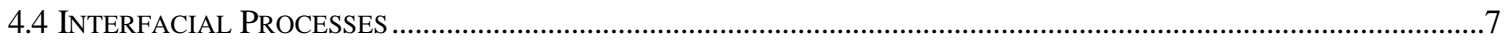

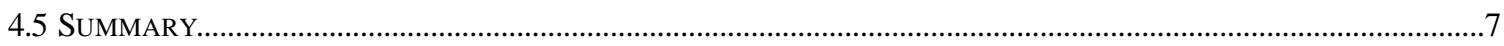

5.0 PROJECT PRODUCTIVITY...............................................................................................................................................8

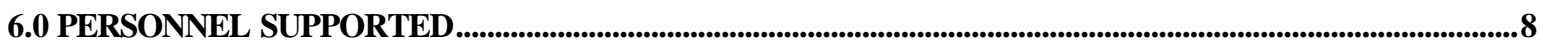

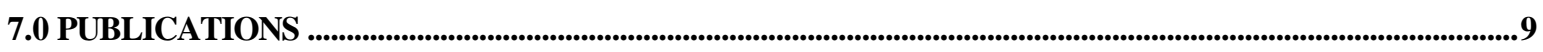

8.0 INTERACTIONS ......................................................................................................................................................10

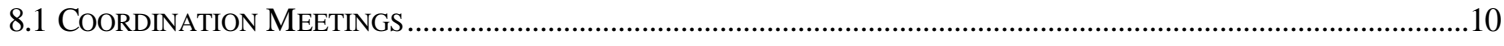

8.2 Presentations in Conferences, Seminars, ETC.....................................................................................

9.0 FUTURE WORK.............................................................................................................................................................................14

10.0 LITERATURE CITED .......................................................................................................................................................................15 


\section{Executive Summary}

The radioactive and chemical wastes present in DOE underground storage tanks contain complex mixtures of sludges, salts, and supernatant liquids. These mixtures, which comprise a wide variety of oxide materials, aqueous solvents, and organic components, are constantly bombarded with energetic particles produced via the decay of radioactive ${ }^{137} \mathrm{Cs}$ and ${ }^{90} \mathrm{Sr}$. These processes

- produce mixtures of toxic, flammable, and potentially explosive gases (i.e., $\mathrm{H}_{\underline{2}}, \mathrm{~N}_{2} \mathrm{O}$, and volatile organics)

- degrade organics, possibly to gas-generating organic fragments, even as the degradation reduces the hazards associated with nitrate-organic mixtures

- alter the surface chemistry of insoluble colloids in tank sludge, influencing sedimentation and the gas/solid interactions that may lead to gas-entrapment phenomena.

At the start of this project, the information available on radiolytic processes in multiphase heterogeneous systems was insufficient to develop accurate safety margins or radiolysis models that adequately described DOE tank waste chemistry to support waste-management decisions. The intent of this program was to establish an understanding of the role of solid-state radiolysis, secondary electron interactions, charge-transfer dynamics, and the general effect of heterogeneous solids (interfaces and particulate surface chemistry) on tank waste radiation processes. Specifically, there was a need to understand the role of interfaces and solids in the generation of noxious gases and the mechanisms of organic-compound degradation.

The interaction of ionizing radiation with nitrate and nitrite solids can contribute to the production of noxious gases in mixed-waste tanks. Low-energy (5 to $100 \mathrm{eV}$ ) electron-beam induced gas generation from the surface of $\mathrm{NaNO}_{3}$ was examined using laser-resonance enhanced multiphoton ionization and quadrupole mass spectrometric detection of the neutral desorption products, post-irradiation temperature-programmed desorption, secondary electron-emission microscopy, and Auger electron spectroscopy. The damage initially involves destruction of the nitrate group via decay of $\mathrm{NO}_{3}{ }^{-*}$ and production of non-thermal $\mathrm{O}$ and $\mathrm{NO}$ fragments. At higher electron fluences, thermalized $\mathrm{NO}$ and $\mathrm{O}_{2}$ are also produced, supposedly due to unimolecular dissociation of $\mathrm{NO}_{3}{ }^{*} \cdot \mathrm{NO}_{2}$ is also detected as a minor product. $\mathrm{O}_{2}$ gas is found escaping from the irradiated $\mathrm{NaNO}_{3}$ in thermal cycling and is associated with thermal decomposition of several radiation defects. These oxidants contribute to the degradation of organic waste constituents, but also help initiate the generation of flammable gas.

Charge transfer across the silica nanoparticle/water interface was studied by picosecond pulse radiolysis using $20-\mathrm{MeV}$ electrons. For the 7 to $22-\mathrm{nm}$ silica particles studied, essentially all electrons generated in the silica cross the interface and appear as hydrated electrons. Organic acceptor molecules adsorbed 
on the silica nanoparticle surface capture these "interfacial" electrons very effectively. In contrast, holes generated in the same solid particles upon absorption of the radiation remain trapped in the solid. For high-level radionuclides stored in suspensions, the presence of particles could promote the generation of water radiolysis products (of particular concern is $\mathrm{H}_{2}$ ) in the vicinity of the particles. This may increase the probability of retention of products near the particles, e.g., by gas-bubble attachment to the particle, and may lead to safety concerns.

The data from this program have improved a predictive computational model of radiation/thermal organic degradation in mixed tanks. 


\subsection{Research Objective}

The purpose of this project was to develop an understanding of radiolysis in systems relevant to nuclear wastes stored in tanks at DOE sites such as Hanford, Savannah River, and Idaho. Since these wastes are highly heterogeneous systems, determining the effects of particulate matter on the radiolytic yields was the main focus of interest. When translated to site-specific concerns, quantitative modeling of these processes can be developed once the fundamental phenomena are understood. Interpretation of the results and conclusions to specific issues, especially safety concerns, at the sites was a major goal. The results were transferred to site operators as soon as the experimental observations were confirmed to be reliable.

\subsection{Methods}

The project was a tight collaboration between the teams at the Notre Dame Radiation Laboratory (NDRL) and PNNL. The collaboration combined the expertise at the NDRL in radiation chemistry with that of the PNNL team in physical organic chemistry and chemical physics specifically of the systems of interest to the EM issues. It utilized the radiation facilities at the NDRL on one hand and surface science facilities of the Environmental and Molecular Sciences Laboratory at PNNL. In addition, the collaboration ensured ready access to the Hanford and Savannah River sites for rapid exchange of information with the site operators and thus speedy implementation of the results to the field operations. Both teams have extensive interaction with the sites dating back to the Tanks Safety Program at Westinghouse Hanford and Savannah River (late 80s, early 90s), focusing on gas-generating tanks and the chemistry of the "organic tanks." The systems of interest remained those with composition typical of waste simulants as defined by Westinghouse Hanford (Meisel et al. 1993). These include high concentrations (few mole/L) of hydroxide, nitrate, and nitrite, and also medium concentrations (tenth mole/L level) of organic complexants and their known degradation products (Webb et al. 1995).

\subsection{Research Results}

The results of this project derive from two very different but fundamentally linked studies of radiolytic processes in heterogeneous systems: 1) electron-beam interactions with $\mathrm{NaNO}_{3}$ crystals and 2) radiation effects in aqueous suspensions of oxide particles. The work involved controlled radiolysis using pulsed, low- (5 to $150 \mathrm{eV}$ ) and high- (3 to $20 \mathrm{MeV}$ ) energy electron beams at Pacific Northwest National Laboratory (PNNL) and at the Radiation Laboratory of the University of Notre Dame, respectively. The low-energy electron irradiation studies suggest that $\mathrm{O}_{2}$ and $\mathrm{NO}$ are the dominant oxidizing species generated by radiolysis of the solid $\mathrm{NaNO}_{3}$ components in tank wastes at the Hanford Waste tanks. These oxidants contribute to the degradation of organic waste constituents, but also help initiate the generation of flammable gas. $\mathrm{NO}_{2}$ is the dominant oxidant in the solution phase, and studies 
focusing on elucidating the kinetics and products of $\mathrm{NO}_{2}$ reactions with organics have been carried out.

\subsection{Electron-Beam Interactions with $\mathrm{NaNO}_{3}$ Surfaces and Interfaces}

The aim of this work was to study electron- and photon-induced degradation of $\mathrm{NaNO}_{3}$ crystals as a function of substrate temperature and to demonstrate the relevance to damage due to radioactive decay processes. $\mathrm{NaNO}_{3}$ crystals were irradiated with an electron and ultraviolet photon beams, and damage was analyzed for substrate temperatures between 100 to $450 \mathrm{~K}$. The experiment using electron beams is schematically depicted in Figure 1a. Figure 1b shows example data obtained, and Figure1c shows a micrograph of an $\mathrm{NaNO}_{3}$ crystal after irradiation. The surface is deeply etched due to electron-induced dissociation of the surface nitrate ions and desorption of neutral fragments.

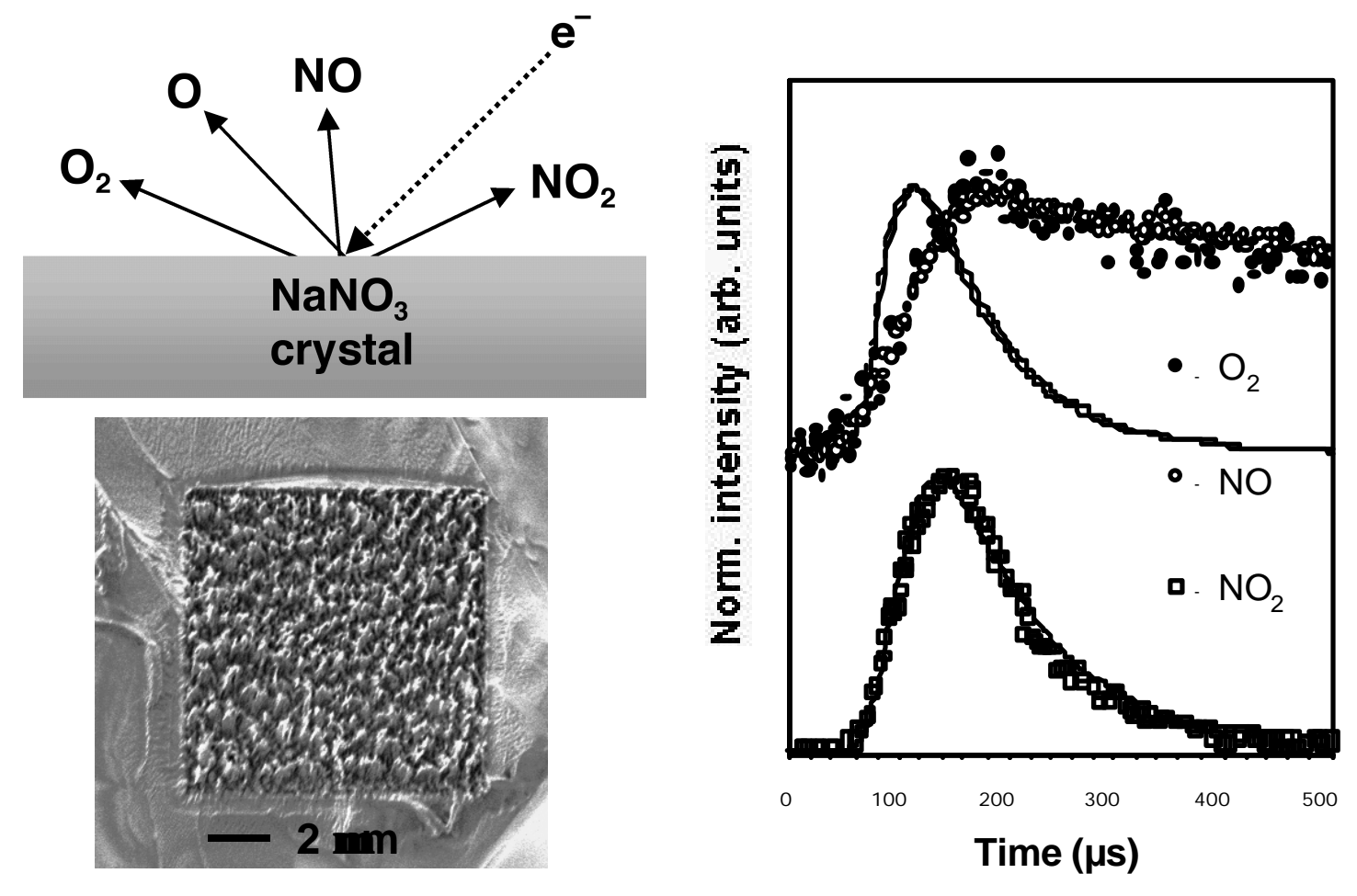

Figure 1. Effects of electron irradiation on the surface of a $\mathrm{NaNO}_{3}$ crystal: (clockwise) schematic depiction of the experiment, time dependence of $\mathrm{O}_{2}, \mathrm{NO}$, and $\mathrm{NO}_{2}$ desorbing from the surface after (pulsed) electron irradiation, and a secondary electron-emission microscopy image of the crystal surface after 10-keV electron irradiation (Petrik et al. 2000).

$\mathrm{NO}$ and $\mathrm{O}_{2}$, the two primary molecular products produced during electron-beam irradiation of $\mathrm{NaNO}_{3}$, were detected via quadrupole mass spectrometry. The formation of $\mathrm{NO}$ and $\mathrm{O}_{2}$ is consistent with our previous work using pulsed low-energy electron and ultraviolet photon irradiation of $\mathrm{NaNO}_{3}$ single 
crystals (Knutsen and Orlando 1996, 1997, 1998). In the case of surface and interface "radiolysis," the $\mathrm{NO}_{2}$ yield is very low in comparison to $\mathrm{O}_{2}$ and $\mathrm{NO}$.

The temperature dependence of the $\mathrm{NO}$ and $\mathrm{O}_{2}$ steady-state electron-stimulated desorption (ESD) rates have also been studied. The rates are identical and can be approximated by the sum of two exponents, $0.16 \pm 0.03$ and $0.010 \pm 0.004 \mathrm{eV}$, which correspond to activation energies for $\mathrm{NO}$ and $\mathrm{O}_{2}$ desorption, respectively. A significant fraction of the $\mathrm{O}_{2}$ molecules produced by radiation defects are initially trapped in the crystal matrix. Molecular oxygen is then released from the crystal during temperature-programmed annealing. The temperature-programmed desorption (TPD) study indicates at least two distinct mechanisms for $\mathrm{O}_{2}$ production and desorption. The high-temperature peak at 340 $\mathrm{K}$ is consistent with decomposition of peroxynitrite $\left(\mathrm{ONOO}^{-}\right)$:

$$
\begin{aligned}
\mathrm{NO}_{3}^{-} * & \rightarrow \mathrm{ONOO}^{-} \\
\mathrm{ONOO}^{-} & \rightarrow \mathrm{NO}_{2}^{-}+\mathrm{O}(\sim 340 \mathrm{~K}) \\
\mathrm{O}+\mathrm{NO}_{3}^{-} & \rightarrow * \mathrm{NO}_{2}^{-}+\mathrm{O}_{2} \\
\mathrm{O}+\mathrm{O} & \rightarrow \mathrm{O}_{2}
\end{aligned}
$$

The sharp low-temperature TPD peak at $240 \mathrm{~K}$ likely corresponds to decay of the caged complex $\left[\mathrm{NO}_{2}{ }^{-} \cdot \mathrm{O}\right]$. This releases an atomic oxygen species that reacts according to Reactions 3 and 4 shown above. In this program, we have shown that $\mathrm{NO}$ is as a major product desorbing from the $\mathrm{NaNO}_{3}$ surface under the electron and UV-photon irradiation. This result is not expected based upon previous bulk radiolysis studies. Organic radicals in the mixed wastes likely participate in the production of $\mathrm{N}_{2} \mathrm{O}$ via the formation of intermediate nitroso-compounds, and oxide interfaces can also catalyze the conversion of $\mathrm{NO} \rightarrow \mathrm{N}_{2} \mathrm{O}$ through $\mathrm{N}_{2} \mathrm{O}_{2}{ }^{-}$transients. Since these $\mathrm{N}_{2} \mathrm{O}$ production channels involve a recombination stage, we expect high $\mathrm{N}_{2} \mathrm{O}$ yields near the $\mathrm{NaNO}_{3}$ interface or between the crystal grains where the local concentration of $\mathrm{NO}$ should be maximum.

The program, which focused on $\mathrm{NaNO}_{3}$ surfaces and interfaces, has also clearly demonstrated that much of the radiation chemistry occurring in these tanks can be simulated by using inelastic scattering of low-energy electrons and ultraviolet photon irradiation methods.

\subsection{Radiolytic Effects of Solid Particles in Suspension}

Many of our accomplishments in this effort were recently summarized in another report in the ACSEMSP Symposium proceedings (Orlando and Meisel 2000). All of these studies involved only silica particles and were aimed at determining if and to what extend energy that is absorbed by the solid particles finds its way out into the water phase. Clearly, if it does, then it will induce aqueous chemical reactions just as in homogeneous solutions.

\subsection{Escape of Electrons from $\mathrm{SiO}_{2}$ Particles (Upper Curve in Figure 2)}


We discovered that the energy that is absorbed by nano-size particles (up to $22 \mathrm{~nm}$ diameter) generates electrons in water just as if the energy is absorbed in water itself. Thus, these solids do not arrest the radiation effects. We emphasize that these observations have far-reaching implications beyond the suspensions and the tanks chemistry. One may view these particles as the "skin" along various other formations (porous grout, micron size powders, etc.).

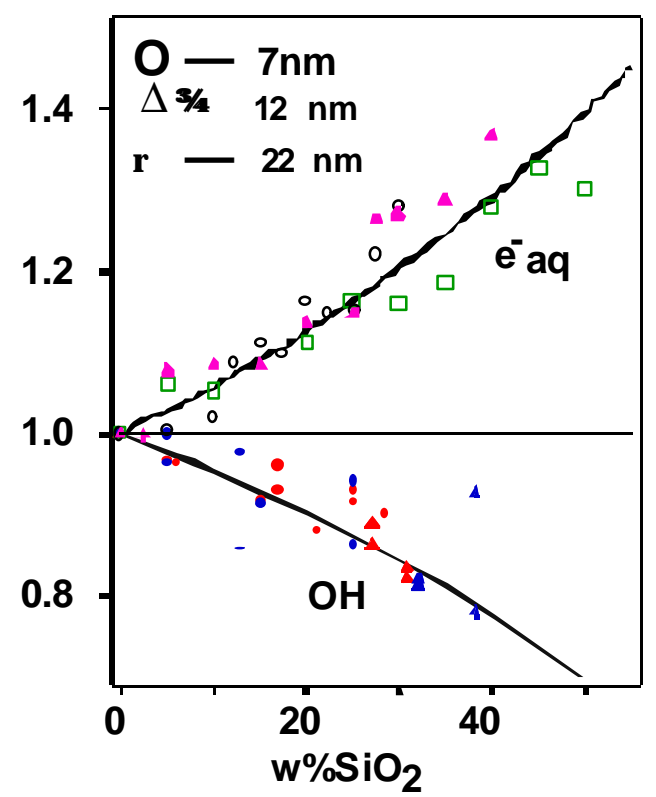

Figure 2: Relative Concentration of $\mathrm{e}_{\text {aq }}^{-}$(upper half) and $\mathrm{OH}$ radicals (lower half) upon increasing $\mathrm{SiO}_{2}$ Concentration. The upper curve is "sample density," indicating the increase in absorbed dose by the sample because of increasing $\mathrm{SiO}_{2}$. The lower curve is "volume fraction of water," indicating the decrease in absorbed dose by the aqueous phase.

\subsection{Trapping of Holes in the Particles (Lower Curve in Figure 2)}

In sharp contrast to the electrons, we discovered that the holes are trapped in the particles before they can oxidize water. Again, this is an observation of far-reaching implications. In the context of organic degradation, it implies that the fraction of energy that is absorbed in such particles cannot contribute to aging via $\mathrm{OH}$ radicals. Direct oxidation of organic substrates by trapped holes is perhaps possible, but then the relevant rates are not those that originate from water fragmentation.

\subsection{Control of Charge Escape by Surface Modifications}

We found that implanting electron acceptors at the surface of the solid particles leads to capture of all of the electrons that would otherwise cross the interface into the water. However, merely changing the surface charge will not affect the escape probability. Thus, on the one hand, one can control the chemical consequences of the suspended particles. On the other hand, the identity of species adsorbed at the surface will determine the chemical consequences. In HLW compositions, where much of the surface is covered with organic deposits, it is unlikely to change the fundamental observation of electron escape from the solid to the water. 


\subsection{Yields of $\mathrm{H}_{2}$ from Aqueous Suspensions}

In addition to electrons and holes, other species may affect the all-important yields of $\mathrm{H}_{2}$. We find no new source of $\mathrm{H}_{2}$ in heavily loaded silica suspensions. On the contrary, we showed that the trapped holes (Section 3.2.2 above) back react with $\mathrm{H}_{2}$ to reduce the yield. However, to avoid misinterpretations, we hasten to emphasize that the increased yield of electrons (Section 3.2.1) can, and will, contribute to increased yields of $\mathrm{H}_{2}$ unless they are eliminated (e.g., by the presence of nitrate in HLW).

\subsection{Relevance and Impact}

Our work is meant to assist in establishing the technical baseline knowledge required to arrive at the rational conclusions on which the decision-making process depends. Accordingly, we elaborate below on issues where such knowledge is critically needed. We describe the specific issues from across the EM Complex that have been or may be impacted by our work. We highlight, though, the issues that still remain unresolved, and we point to where we believe the follow-on work could contribute to their resolution.

\subsection{Gas Generation and Organic/Nitrate Tanks at EM sites}

Issues relating to the Hanford and Savannah River tank wastes include the ignition of flammable gas mixtures in tank head-space, ignition of organic solvents present in floating layers atop the aqueous wastes, ignition of combustible solid wastes containing organic complexants mixed with nitrate/nitrite salts, and spontaneous bulk runaway chemical reactions. The Hanford organic/nitrate issue was brought to a closure, and we indicated in the Results section above where our efforts contributed to that resolution (Meacham et al. 1998). The eruptive gas-release events in the tanks raised concern that $\mathrm{H}_{2}$ (and $\mathrm{NH}_{3}$ ) may ignite because they often were well within the flammability boundaries of $\mathrm{H}_{2}$ in $\mathrm{N}_{2} \mathrm{O}$. A recent report aimed at closure of the gas-generation issue (Stock 2000) emphasizes the tight correlation between the rate of gas generation and organic oxidations and degradation in HLW. As is always the case in fuel gas generation, a reduction process, it must be coupled to an oxidation process. Predictive capabilities for one process assist in the predictability of the other. Our early efforts correlated the gasgeneration rate with the hydrogen content of the organics in the waste. Much effort that followed correlated the radiolytic gas-generation rates with the total organic carbon (TOC) and eventually led to a model that realistically predicts these rates to within a factor of two for many of the tanks. The prospects for closure of the Flammable-Gas issue at Hanford this fiscal year now seem rather promising. This feat would have been impossible without the scientific basis laid by the effort of this program and its predecessors. 


\subsection{Organic Layer in the Tanks at the Idaho National Engineering Laboratory (INEL)}

This issue was of significant concern at the time of the original proposal. ${ }^{\text {(a) }}$ A separate organic layer develops in the tanks of the new Waste Calcining Facility at the INEL. Similar concerns existed at Hanford as well. The concern is similar to the one discussed above, except that the radiation is primarily absorbed by the floating organic layer material rather than by water. We have enough information within our records to provide realistic estimates of $\mathrm{H}_{2}$ yields in such situations, provided we know the dose in these layers. To the best of our knowledge, the issue at Hanford was resolved (Cowley et al. 1998). However, single-shell tanks that contain floating organic layers will require removal of the layer to stabilize the tank, an operation that may bring the issue back to the front.

\subsection{Characterization Efforts}

One motivation for the original proposal was our attempt to assist in the waste-characterization effort, which in turn was driven by the need to address storage safety issues. Closure of the Organic Tanks safety issue required a significant characterization effort. Samples from many of the tanks with high TOC were analyzed to identify and quantify the majority of organic compounds present. We have shown that degradation of waste stimulants under storage conditions leads to oxidization of the organic chelators. Consequently, their fuel value decreases with time, and with exception of oxalate ion, the organic end products are water-soluble. Knowledge of the oxidation mechanism was helpful in development of appropriate organic analytical methods. Furthermore, the analytical results that found a wide variety of compounds not originally used in nuclear materials production processes could be rationalized using the information obtained from our laboratory studies of waste simulants.

At present, the characterization effort is focused on supporting waste-retrieval and treatment activities. Analyzes are being performed to identify trace hazardous chemicals present in the wastes (Evans et al. 2000). A rationale for the presence, and often the absence, of various chemicals is needed to satisfy federal and state regulators. Therefore, the predictive options that our effort offer become rather significant. Conversely, the inability to provide reliable composition information on the HLW is alarming to the Defense Nuclear Facilities Safety Board (DNFSB). ${ }^{\text {(b) }}$ As our efforts, along with the efforts of the Organic Aging Program at Hanford demonstrated, the speciation of the final degradation products of the aging process can be determined, either by radiolytic or by $\mathrm{NO}_{2}$ contact experiments (Camaioni et al.

(a) J. T. Conway; Chairman, D. Letter dated October 13, 1995, from J. T. Conway, Chairman DNFSB, to DOE Assistant Secretary T. P. Grumbly, and Memo from D. G. Ogg to the Board Members on the Chemical Processing at the New Waste Calcining Facility at the NEL dated September 19, 1995.

(b) J. T. Conway; Chairman, D. Letters from John T. Conway, Chairman, DNFSB to Assistant Secretary for EM, Thomas P. Grumbly, dated March 1, 1996, and memo from Ralph Arcaro to G. W. Cunningham, Technical Director, DNFSB, dated January 12, 1996, on characterization efforts." 
1998; Meisel et al. 2000; Meisel and Orlando 2000). Proposed degradation mechanisms (Meisel et al. 1993) and aging experiments actually identified intermediate nitro, nitroso, and oxime functionalities (Camaioni et al. 1994, 1995), but the related rates and in particular, computational predictive capabilities are still to be demonstrated.

\subsection{Interfacial Processes}

The need to understand the processes in heterogeneous systems, and before that simply establishing the facts, hardly needs justification. Solid interfaces in contact with water are commonplace throughout the Complex. They are obviously present in the tanks, and they affect gas generation (via absorption of the radiation and catalysis at the interface). They appear at porous waste-storage formations (e.g., grout) and at cracks in glasses. Transportation of wet powders of spent fuel, temporarily stored in canisters at Rocky Flats, was delayed because of concerns of $\mathrm{H}_{2}$ ignition when opened upon arrival at the Savannah River site. A similar situation pertains with the 94-1 issue at Los Alamos. Many of the concerns related to gas generation at wet interfaces were discussed at a recent Gas Generation Meeting in Savannah River (August 13, 1999) and again at the symposium on Gas Generation at the American Nuclear Society meeting in Long Beach, CA (November 14-18, 1999). It is clear that information on the basic facts of the yields and rates of gas generation at the interface, especially at low levels of wetting, is lacking. Our program provided this information (albeit still at merely an empirical level), along with some insight into the mechanistic origin. Efforts at Los Alamos and NDRL are now underway to elaborate on the basic observations provided by our program.

The nanoparticle-radiolysis results have many practical implications. Most obviously, the storage of nuclear material in an "inert" matrix of small particles or large specific surface areas (e.g., grout) may lead to adverse effects. If the particles are small, the enhanced absorption of energy in the matrix will lead to more pronounced aqueous radiation chemistry. For high-level radionuclides stored in suspensions in large tanks, the presence of the particles will promote generation of water radiolysis products (of particular concern is $\mathrm{H}_{2}$ ) in the vicinity of the particles. This may increase the probability of retention of products near the particles, for example, by gas-bubble attachment to the particle, and may lead to serious safety concerns. On the other hand, ionizing irradiation is often considered a viable advanced oxidation technique in various cleanup operations, such as water decontamination or soil

remediation. Such a radiocatalytic approach, analogous to the proliferating photocatalysis, will clearly be most efficient with small particles.

\subsection{Summary}

The underlying chemistry of high-level liquid waste is the radiation chemistry of the $\mathrm{NO}_{\mathrm{x}}$ radicals in highly concentrated and often heterogeneous systems. Quantitative understanding of these processes continues to prove crucial in resolving safety issues associated with storing the waste in the tanks. Some of the concerns that this chemistry raises were addressed and resolved in this and companion projects, " $\mathrm{NO}_{\mathrm{x}}$ Chemistry of Nuclear Waste (55229)" and "Mechanisms and Kinetics of Organic Aging in HLW 
(65408)." Many issues need to be further explored. A renewal extension of project 55229 was submitted and recently granted. Project 65408 has submitted a proposal for renewal. The projects have complementary objectives to transform as much as possible of the effort fom the laboratory experimental level to the computational regime.

\subsection{Project Productivity}

The project achieved many of its objectives as discussed in the previous Section. In particular, its impact on the Safety issues at Hanford is clear. Several changes were made during the project lifetime in response to changing circumstances. The tetraphenylborate (TPB) issue was not addressed during the project, even though it was outlined in the original proposal as a possible direction. This issue became less important as the major source for the benzene was determined to be chemical catalysis and not radiolysis, and use in the "In Tank Precipitation" process was put on hold. On the technical level, the exact chemistry that will occur in each tank will depend on specific parameters relevant to that particular tank. The most important parameters include the water content, nitrate/nitrite concentrations, $\mathrm{pH}$, organic content, and fraction of solid. Therefore, our efforts cannot provide a response to each scenario that may happen in various tanks. Rather, we offer the underlying principles and demonstrate their dependence on composition. The recently renewed project, " $\mathrm{NO}_{\mathrm{x}}$ and Heterogeneous Chemistry of Nuclear Waste," proposes to develop a computational effort that will design computationaltheoretical algorithms that could respond to these various scenarios.

\subsection{Personnel Supported}

K. Knutsen (Assoc. Western Universities - Postdoctoral Fellow)

N. Petrik (Assoc. Western Universities - Visiting Research Scientist, now at Pacific Northwest National Laboratory)

A. R. Cook (Argonne National Laboratory - Postdoctoral fellow, now at Brookhaven National Laboratory)

N. Dimitirievic (Argonne National Laboratory - Visiting Scientist)

T. Schatz (Argonne National Laboratory - Postdoctoral Fellow)

A. Henglein, (Notre Dame Radiation Lab, Visiting Prof. from the Hahn-Meitner Institute, Berlin, now retired)

N. Zevos (State University - New York, Potsdam - Visiting Prof., now retired.)

E. Paparazzo (Istituto di Struttura della Materia del CNR, Roma, Italy - Visiting Scientist)

S. Lea (Pacific Northwest National Laboratory - Scientist)

A. K. Sharma (Now at Rhodia, Inc., Cranbury, NJ - Scientist) 


\subsection{Publications}

CHEMISTRY, RADIATION, AND INTERFACES IN SUSPENSIONS OF NUCLEAR WASTE SIMULANTS

D. Meisel, A. R. Cook, D. Camaioni, and T. M. Orlando, Photoelectrochemistry, K. Rajeshwar, L. M. Peter, A. Fujishima, D. Meissner, and M. Tomkiewicz, Eds. Electrochemical Society, Vol. 97-20: 350-7 (1997).

LOW-ENERGY ELECTRON- AND ULTRAVIOLET (6.4 EV) PHOTON-STIMULATED

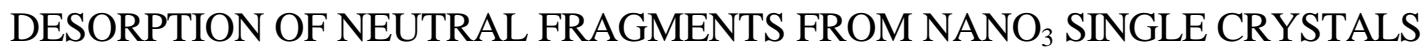

K. Knutsen, and T. M. Orlando, Appl. Surf. Sci. 127:1 (1998).

CHARGE TRANSFER ACROSS THE SILICA NANOPARTICLE/WATER INTERFACE

T. Schatz, A. R. Cook, and D. Meisel, J. Phys. Chem., 102:7225-30 (1998).

CHARGE SEPARATION ACROSS THE SILICA NANOPARTICLE/WATER INTERFACE

N. M. Dimitrijevic, A. Henglein, and D. Meisel, J. Phys. Chem. B, 103, 7073-6 (1999).

CAPTURE OF CHARGE CARRIERS AT THE SILICA NANOPARTICLE - WATER INTERFACE

T. Schatz, A. R. Cook, and D. Meisel, J. Phys. Chem. B, 103, 10209-13 (1999).

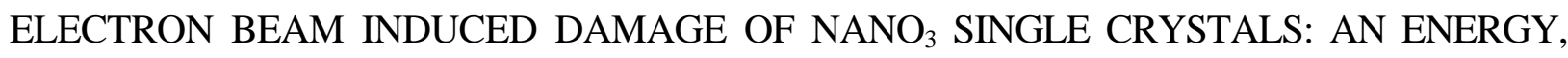
TEMPERATURE AND QUANTUM-STATE RESOLVED STUDY

N. G. Petrik, K. Knutsen, D. Camaioni, S. Lea, E. Papparazzo, and T. M. Orlando, J. Phys. Chem. B, 104, 1563 (2000).

RADIATION-INDUCED PROCESSES IN AQUEOUS SUSPENSIONS OF NANOPARTICLES AND IN NANOSCALE WATER FILMS: RELEVANCE TO THE PRODUCTION OF HYDROGEN IN SPENT NUCLEAR FUEL

T. M. Orlando and D. Meisel, Chapter 17, P. Gary Eller and W. R. Heineman, Nuclear Site Remediation: First Accomplishments of the Environmental Management Science Program, ACS Symposium Series 778, Publisher, American Chemical Society, Washington, DC (2000).

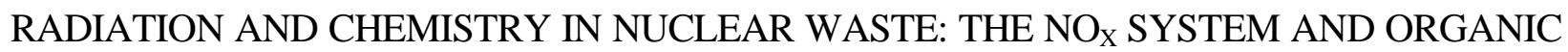
AGING

D. Meisel, D. Camaioni, and T. M. Orlando, Chapter 21, P. Gary Eller and W. R. Heineman, Nuclear Site Remediation: First Accomplishments of the Environmental Management Science Program, ACS Symposium Series 778, Publisher, American Chemical Society, Washington, DC (2000). 


\section{RADIATION INDUCED CHARGE CARRIERS IN AQUEOUS SUSPENSIONS OF NANOPARTICLES}

Dan Meisel, Proceedings of the Trombay Symposium on Radiation and Photochemistry, Volume II, 271-9.

\subsection{Interactions}

This project and the Notre Dame EMSP project, "The $\mathrm{NO}_{\mathrm{x}}$ System in Nuclear Waste," are strongly coupled with the "Waste Aging Studies" project at the Hanford Site such that the basic studies are performed at Notre Dame and PNNL, and the information is continuously shared with the Tank Waste Safety Program. Information from the projects is also shared directly with Westinghouse Savannah River staff. To further facilitate the exchange of information and the immediate incorporation of results into operations, we conduct at least semi-annual "coordination meetings" in which the site operators (e.g., from DESH, Numatec, WSRC, etc.) participate both as contributors and as observers. In addition, we participate in national and international meetings of scientific societies, such as the American Chemical Society, the Electrochemical Society, the American Physical Society, the American Nuclear Society, and the IEEE. We also publish essentially all of our work in the open literature (see Section G).

\subsection{Coordination Meetings}

Coordination meeting at the Environmental Molecular Science Laboratory, PNNL Richland, Washington, April 29-30, 1999. Present all PIs, Co-PIs and associated PNNL staff of the three projects, representatives of Tank Waste Focus Area, DOE-RL consultants; additional personnel from NDRL and PNNL.

Presentation by D. Meisel on "Fundamentals of Radiation Effects in Heterogeneous Systems" in Aiken, South Carolina, at the Rocky Flats - Savannah River meeting on Gas Generation, Aug. 13, 1999. Present representatives from Savannah River, Rocky Flats, LANL, ORNL, Co-PIs from NDRL, consultants.

Coordination Meeting in conjunction with the Symposium on "The Environmental Management Science Program," ACS Meeting, New Orleans, Louisiana, August 22-26, 1999.

Present all PIs and Co-PIs of the three EMSP projects and few other PIs from NDRL, BNL, and PNNL.

Coordination meeting at the Notre Dame Radiation Lab, October 29-30, 1998. Present: All PIs and associated NDRL staff, theoretical component from EMSL. 
ANL, April 23-24, 1998. All PIs, associated ANL staff, representatives from Duke Eng. Hanford, Westinghouse Savannah River, Brookhaven National Laboratory.

Coordination Meeting in conjunction with PNNL's review of their EMSP Projects at the EMSL, PNNL, Richland, Washington, Feb. 19-21, 1998. Present all PIs of the three projects, other PNNL EMSP PIs, representatives from Duke Engineering, Numatec, DOE-RL consultants, and others.

Coordination meeting at PNNL, Richland, Washington, April 22-23, 1997. Present all PIs of the three projects, other PNNL - EMSP PIs, EMSL Acting Director representatives from Duke Engineering, Numatec, DOE-RL consultants, and others.

Coordination meeting at ANL, May 11-12, 1997. Present: All PIs and associated ANL staff, collaborators from State University of New York.

Start of project coordination meeting, ANL, October 25, 1996. Present: All PIs and related staff.

\subsection{Presentations in Conferences, Seminars, etc.}

\section{CHARGE CARRIERS IN NANOPARTICLES}

D. Meisel, Invited Talk, Fry Award Symposium of the 2000 Annual Radiation Research Society, Meeting, Albuquerque, NM, Apr. 29-May 3, 2000.

\section{RADIOLYTIC AND THERMAL PROCESSES IN HOMOGENEOUS AND HETEROGENEOUS HIGH LEVEL WASTE}

D. M. Camaioni and Dan Meisel, Invited Talk, Annual Meeting of the Environmental Management Science Program, Atlanta, Georgia, April 25-28, 2000.

\section{RADIOLYTIC HYDROGEN GENERATION IN HETEROGENEOUS SYSTEMS}

H. Miyoshi, T. Schatz and D. Meisel, Invited Talk, Symposium on "Long Term Disposition," Nuclear Division, ACS annual meeting, San Francisco, California, March 26-30, 2000.

\section{THE AGING OF ORGANIC CHEMICALS IN HANFORD HIGH-LEVEL WASTES}

H. Babad and D. M. Camaioni, DOE Waste Management 2000 Conference, Tuscon, Arizona, March 2, 2000.

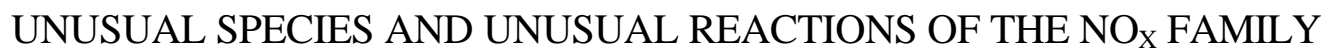

D. Meisel, Inorganic Section Seminar, Department of Chemistry and Biochemistry, University of Notre Dame, Indiana, Dec. 3, 1999.

\section{GAS GENERATION FROM SOLIDS IN AQUEOUS SUSPENSIONS}

D. Meisel and T. Schatz, Invited Talk, Annual Meeting, Am. Nuclear Soc., Long Beach, California, November 14-18, 1999. 
RADIOLYTIC EFFECTS IN HOMOGENEOUS AND HETEROGENEOUS HIGH LEVEL SIMULANTS

D. Meisel, D. M. Camaioni, and T. Orlando, Invited Talk, Symposium on "The Environmental Management Science Program," Annual Meeting, Am. Chem. Soc., New Orleans, Louisiana, August 22-26, 1999.

RADIOLYTIC EFFECTS ON ORGANIC CHEMICALS IN HIGH LEVEL WASTES

D. M. Camaioni, A. K. Sharma, J. C. Linehan, T. Orlando, N. Zevos, and D. Meisel, Symposium on "The Environmental Management Science Program," Annual Meeting, Am. Chem. Soc., New Orleans, Louisiana, August 22-26, 1999.

RADIATION INDUCED CHARGE CARRIERS IN NANOPARTICLE SUSPENSIONS

D. Meisel, Radiation Research Congress, Dublin, Ireland, July 16-24, 1999.

REACTIONS OF $\mathrm{NO}_{2}$ WITH ORGANIC COMPLEXANTS IN ALKALINE SOLUTIONS

D. M. Camaioni, A. K. Sharma, J. C. Linehan, N. Zevos, D. Meisel, Invited Talk, Symposium on "Free radicals in the Condensed Phase," Annual Meeting, Am. Chem. Soc., Anaheim, California, March 21-25, 1999.

RADIOCATALYSIS: FUNDAMENTALS AND APPLICATIONS:

D. Meisel, Seminar, Northwestern University, Evanston, Illinois, February 10, 1999.

CHARGE CARRIER ACROSS INTERFACES.

D. Meisel, School of Engineering, Notre Dame, September 15, 1998

INTERFACIAL CHARGE TRANSFER IN IRRADIATED SUSPENSIONS. IMPLICATIONS TO NUCLEAR WASTE

T. Schatz, A. R. Cook, and D. Meisel, Symposium on "Actinide Solution Chemistry," Annual Meeting, Am. Chem. Soc., Boston, Massachusetts, Aug. 23-27, 1998.

INTERFACIAL CHARGE TRANSFER ACROSS THE NANOPARTICLE INTERFACE

D. Meisel, Seminar, Chemistry Department, University of Notre Dame, Notre Dame, Indiana, May 25, 1998.

RADIATION AND CHEMISTRY IN THE MANAGEMENT OF NUCLEAR WASTE. COLLOIDS, INTERFACES, AND RADICALS

D. Meisel, Invited Talk, "Research Needs and Opportunities in Radiation Chemistry," DOE Workshop, Chesterton, Indiana, April 19-22. 1998.

RADIATION AND CHEMISTRY IN THE NUCLEAR ARENA: RADICALS, PARTICLES AND INTERFACES 
D. Meisel, Seminar, Radiation Laboratory, University of Notre Dame, Notre Dame, Indiana, April 2, 1998.

SCIENCE, TECHNOLOGY AND THE PUBLIC IN THE MANAGEMENT OF NUCLEAR WASTE

D. Meisel, Environmental Sciences Seminar, University of Wisconsin, Madison, Wisconsin, Nov. 6, 1997.

FATE OF ORGANIC Chemicals ADDED TO HANFORD HIGH LEVEL WASTE STORAGE TANKS

Symposium on Future Directions in Radioactive and Mixed Waste Management, 214th ACS National Meeting, Sept 9, 1997, Las Vegas, Nevada.

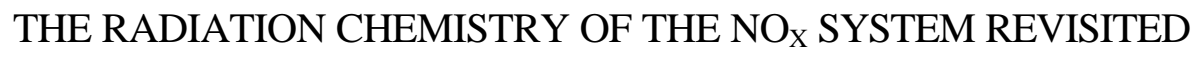

A. R. Cook, L. A. Curtiss, B. Dryefus, D. M. Camaioni and D. Meisel, Annual Meeting, Am. Chem. Soc., Las Vegas, Nevada, Sept. 7-11, 1997.

SOME FUNDAMENTAL STUDIES ON THE EFFECTS OF RADIATION AND INTERFACES IN HIGH LEVEL WASTES

D. M. Camaioni, K. Knutsen, J. C. Linehan, T. M. Orlando, A. Cook, and D. Meisel, Annual Meeting, Am. Chem. Soc., Las Vegas, Nevada, Sept. 7-11, 1997.

CHEMISTRY, RADIATION, AND INTERFACES IN SUSPENSIONS OF NUCLEAR WASTE SIMULANTS

D. Meisel, Joint Meeting of the Electrochemical Societies, Paris, France, Aug. 31-Sep. 5, 1997.

ORGANIC AGING IN HANFORD WASTE TANKS

D. Camaioni, Hanford Tank Waste Safety Technical Exchange, June 2, 1998.

RADIOLYTIC AGING

D. Camaioni, Workshop on the Safety Issue Resolution and Characterization Implementation Project, Nov. 16, 1996, Richland, Washington.

NONTHERMAL SURFACE PROCESSES IN THE GENERATION OF GAS IN MIXED WASTES

T. M. Orlando, N. Petrik, S. Marshman, and D. M. Camaioni, Invited talk, Annual Meeting, Am. Nuclear Soc., Long beach, California, November 14-18, 1999.

INTERFACIAL RADIOLYSIS EFFECTS RELEVANT TO SPENT NUCLEAR FUEL AND MIXED RADIOACTIVE WASTE STORAGE

N. Petrik, S. Marshman, D. M. Camaioni, and T. M. Orlando, Annual Symposium on "First Accomplishments of the Environmental Management Science Program," Annual Meeting, Am. Chem. Soc., New Orleans, Louisiana, August 22-26, 1999. 
IONIZING RADIATION INDUCED CHARGE CARRIERS IN COLLOIDAL NANOPARTICLE SURFACES

D. Meisel, Invited Talk, Symposium on "Nanomaterials for Energy Conversion," at the $195^{\text {th }}$ Meeting of the Electrochemistry Society, Seattle, WA, May 2-7, 1999.

RADICALS FROM IONIZING RADIATION IN SUSPENSIONS OF NANOPARTICLES

T. Schatz, D. Meisel, and A. Cook, Invited Talk, Symposium on "Free radicals in the Condensed Phase," Annual Meeting, Am. Chem. Soc., Anaheim, California, March 21-25, 1999.

\section{QUANTUM STATE-RESOLVED DESORPTION STUDIES OF WIDE BAND-GAP} MATERIALS

T. M. Orlando, Invited talk, Dept of Physics, Rutgers, The State University of New Jersey, Piscatawy, New Jersey, Jan. 15, 1998.

\section{QUANTUM STATE-RESOLVED DESORPTION STUDIES OF WIDE BAND-GAP MATERIALS}

T. M. Orlando, Invited talk, Dept. of Physics and Astronomy, Nanophysics Laboratory, Univ. of Birmingham, Birmingham, UK, June 8, 1998.

\subsection{Future Work}

This EMSP program has branched off into several new directions. Specifically, results obtained in this program led to the submission of a FY99 proposal entitled "Effects of Water Radiolysis in Water Cooled Nuclear Reactors" to the Nuclear Energy Research Initiative by Pimblott, LaVerne and Miesel (Univ. of Notre Dame) and Orlando (PNNL). Results were also incorporated into an EMSP program entitled "Mechanisms and Kinetics of Organic Aging in High-Level Wastes," PI-D. M. Camaioni (PNNL). This project combines the kinetics of radiolytically induced organic reactions with the kinetics of thermally activated organic reactions to develop global models for organic degradation in nuclear wastes. Finally, a collaborative effort has started to theoretically characterize organic intermediates generated in HLWs. This work involves PIs of this project and theorist colleagues at PNNL and NDRL. The effort, being directed under the renewed " $\mathrm{NO}_{\mathrm{x}}$ Chemistry in Nuclear Waste" EMSP project, will foster understanding of organic aging and the development of mechanistic kinetic models by calculating thermochemical properties that are difficult to measure by experiment. 


\subsection{Literature Cited}

Camaioni, D. M., W. D. Samuels, D. D. Lenihan, S. A. Clauss, K. L. Wahl, J. A. Campbell. 1994. Organic Tanks Safety Program Waste Aging Studies, PNL-10161, Pacific Laboratory, Richland, Washington.

Camaioni, D. M., W. D. Samuels, S. A. Clauss, D. D. Lenihan, K. L. Wahl, J. A. Campbell, and W. J. Shaw. 1995. Organic Tanks Safety Program FY95 Waste Aging Studies, PNL-10794, Pacific National Laboratory, Richland, Washington.

Camaioni, D. M., W. D. Samuels, J. C. Linehan, A. K. Sharma, A. T. Autrey, M. A. Lilga, M. O. Hogan, S. A. Clauss, K. L. Wahl, and J. A. Campbell. 1998. Organic Tanks Safety Program Waste Aging Studies Final Report, PNL-11909, Rev. 1, Pacific Northwest National Laboratory, Richland, Washington.

Cowley, W. L., J. E. Meacham, J. M. Grigsby, and A. K. Postma. 1998. Organic Solvent Topical Report, HNF-SD-WM-CN-032, Rev. 1, Duke Engineering and Services Hanford, Inc., Richland, Washington.

Evans, J. C., et al. 2001. Organic Analysis of C-104, WTP-RPT-00 8, Rev. 1, Pacific Northwest National Laboratory, Richland, Washington.

Knutsen, K., and T. M. Orlando. 1998. "Low-Energy (5 - $100 \mathrm{eV)}$ Electron- and Ultraviolet (6.4 eV) Photon-Stimulated Desorption of Neutral Fragments from $\mathrm{NaNO}_{3}$ Single Crystals." Appl. Surf. Sci. 127-129, 1-6.

Knutsen, K., and T. M. Orlando. 1996. "Low-Energy (5 - $80 \mathrm{eV})$ Electron-Stimulated Desorption of $\mathrm{H}^{+}\left(\mathrm{D}^{+}\right), \mathrm{OH}^{+}\left(\mathrm{OD}^{+}\right), \mathrm{O}^{+}$, and $\mathrm{NO}^{+}$from Solution-Grown $\mathrm{NaNO}_{3}$ Crystals." Surf. Sci. 348, $143-$ 152.

Knutsen, K., and T. M. Orlando. 1993. Photon-Stimulated Desorption of $\mathrm{O}\left({ }^{3} P\right)$ and $\mathrm{NO}^{2}\left({ }^{2}\right)$. Phys. Rev. B 55, 13246-13252 (1997). D. Meisel, C. D. Jonah, S. Kapoor, M. S. Matheson, and M. C. Sauer, Jr. Radiolytic and Radiolytically Induced Generation of Gases from Synthetic Wastes, ANL-93/43, Argonne National Laboratory, Argonne, Illinois.

Orlando, T., and D. Meisel. 2000. In Nuclear Site Remediation; P. G. Eller, and W. R. Heinman, Eds. ACS Symposium Series, 2000; Vol. 778.

Meacham, J. E., A. B. Webb, N. W. Kirch, J. A. Lechelt, D. A. Reynolds, G. S. Barney, D. M. Camaioni, F. Gao, R. T. Hallen, and P. G. Heasler. 1998. Organic Complexant Topical Report, HNF-SD-WM-CN-058 Rev. 2, DE\&S Hanford, Richland, Washington. 
Meisel, D., D. Camaioni, and T. M. Orlando. 2000. "Radiation and Chemistry in Nuclear Waste: The $\mathrm{NO}_{\mathrm{x}}$ System and Organic Aging," Chapter 21, P. Gary Eller and W. R. Heineman, Nuclear Site Remediation: First Accomplishments of the Environmental Management Science Program, ACS Symposium Series 778, Publisher, American Chemical Society, Washington, DC.

Orlando, T. M., and D. Meisel. 2000. "Radiation-Induced Processes in Aqueous Suspensions of Nanoparticles and in Nanoscale Water Films: Relevance to the Production of Hydrogen in Spent Nuclear Fuel." Chapter 17, P. Gary Eller and W. R. Heineman, Nuclear Site Remediation: First Accomplishments of the Environmental Management Science Program, ACS Symposium Series 778, Publisher, American Chemical Society, Washington, DC.

Petrik, N. G., K. Knutsen, D. Camaioni, S. Lea, E. Papparazzo, and TM Orlando. 2000. "Electron Beam Induced Damage of $\mathrm{NaNO}_{3}$ Single Crystals: An Energy, Temperature and Quantum-State Resolved Study," J. Phys. Chem. B, 104, 1563.

Stock, L. M. 2000. “The Chemistry of Flammable Gas,” RPP-6664, CH2M HILL Hanford Group, Inc., Richland, Washington.

Meisel, D., C. D. Jonah, S. Kapoor, M. S. Matheson, and M. C. Sauer, Jr. 1993. Radiolytic and Radiolytically Induced Generation of Gases from Synthetic Wastes, ANL-93/43, Argonne National Laboratory, Argonne, IL.

Webb, A. B., J. L. Stewart, D. A. Turner, M. G. Plys, B. Malinovic, J. M. Grigsby, D. M. Camaioni, P. G. Heasler, W. D. Samuels, and J. J. Toth. 1995. Preliminary Safety Criteria for Organic Watch List Tanks at the Hanford Site. WHC-SD-WM-SARR-033 Rev. 0, Westinghouse Hanford Company, Richland, WA 99352. 